\title{
Serum levels of VEGF and bFGF in infantile hemangiomas treated with propranolol
}

\author{
Hilal Susam Şen ${ }^{1 \oplus}$, Bilgehan Yalçın² ${ }^{2 \oplus}$, Hande Canpınar $^{3 \oplus}$, Süheyla Ocak ${ }^{4}$, \\ Canan Akyüz ${ }^{20}$ \\ ${ }^{1}$ Division of Pediatric Oncology, İstanbul Okmeydanı Training and Research Hospital, İstanbul; ${ }^{2}$ Department of Pediatric Oncology, \\ Hacettepe University Faculty of Medicine, Ankara, ${ }^{3}$ Department of Basic Oncology, Hacettepe University Cancer Institute, Ankara; \\ ${ }^{4}$ Department of Pediatric Hematology and Oncology, İstanbul University İstanbul Medical Faculty, İstanbul, Turkey.
}

\begin{abstract}
Background. Infantile hemangiomas $(\mathrm{IH})$ represent the most common type of benign tumors of infancy. Vascular endothelial growth factor (VEGF) and basic fibroblastic growth factor (bFGF) have a central role in the pathogenesis of infantile hemangiomas.

Methods. In this prospective study, we aimed to investigate the relationship between serum VEGF and bFGF levels and clinical characteristics and the serological changes in VEGF and bFGF levels associated with propranolol treatment in infants diagnosed with IH. Blood samples were taken from 34 patients with IH and 10 controls. Serum VEGF and bFGF levels were studied by ELISA.

Results. At initial diagnosis, median serum bFGF levels were $11.1 \mathrm{ng} / \mathrm{ml}(4.8-16.6)$ in patients with $\mathrm{IH}(\mathrm{n}=34)$ and $2.6 \mathrm{ng} / \mathrm{ml}(1.7-4.7)$ in controls $(\mathrm{p}<0.001)$, and, median serum VEGF levels for same groups were $58.5 \mathrm{ng} / \mathrm{ml}$ $(25.3-190.2)$ and $11.4 \mathrm{ng} / \mathrm{ml}(8.2-19.8)(\mathrm{p}<0.001)$, respectively. Serum VEGF and bFGF levels were not correlated. In 18 infants who were treated with propranolol with serial measurements, median serum bFGF levels were $10.7 \mathrm{ng} / \mathrm{ml}, 9.8 \mathrm{ng} / \mathrm{ml}$ and $10.5 \mathrm{ng} / \mathrm{ml}(\mathrm{p}=0.8)$, and median serum VEGF levels were $68.6 \mathrm{ng} / \mathrm{ml}, 63.5 \mathrm{ng} / \mathrm{ml}$ and $45.1 \mathrm{ng} / \mathrm{ml}(\mathrm{p}<0.001)$ at initial diagnosis, at first and third months, respectively. Median regression rates of the hemangiomas at the first and third months were $-\% 47.3$ and $-\% 58.3(\mathrm{p}<0.001)$, respectively.
\end{abstract}

Conclusions. Serum bFGF levels didn't change in time. Serum VEGF levels seemed to follow the natural course of IH and might be a marker for follow-up. The contribution of propranolol treatment should also be considered.

Key words: basic fibroblastic growth factor (bFBF), infantile hemangioma, propranolol, treatment, vascular endothelial growth factor (VEGF).

Infantile hemangiomas $(\mathrm{IH})$ represent the most common type of benign tumors of infancy with an estimated prevalence of $1-10 \% .^{1}$ An impaired balance between proangiogenic and antiangiogenic factors in a background of hypoxia has been implicated in the pathogenesis of $\mathrm{IH}^{2,3}$ Numerous stimulants and inhibitors have been discovered in humans; vascular endothelial growth factor (VEGF) and basic

৫ilal Susam Şen

hilalsusam@hotmail.com

Received 17th December 2019, revised 15th April 2020, accepted 16th April 2020.

This article was presented at 19th National Pediatric Oncology Congress, İzmir, 2016. fibroblastic growth factor (bFGF) appear to be essential for vasculogenesis and angiogenesis. ${ }^{4}$ Although bFGF acts synergistically with VEGF, variable results have been reported in studies regarding serum bFGF levels in IH. ${ }^{5,6}$ Propranolol being a nonselective beta-blocker has become the first choice of therapy for IH.-9 The mechanism of action of propranolol on $\mathrm{IH}$ remains elusive. ${ }^{6}$

In this prospective study, we aimed to investigate the relationship between serum VEGF and bFGF levels and clinical characteristics as well as the serological changes in VEGF and bFGF levels associated with propranolol treatment in infants with $\mathrm{IH}$. 


\section{Material and Methods}

Between September 2013 and September 2014, 34 newly diagnosed cases of $\mathrm{IH}$ and 10 agematched healthy controls were enrolled in the study. All patients had cutaneous hemangiomas at proliferation phase and none had received any previous treatment or underwent any local interventions for the hemangiomas. Proliferation phase of $\mathrm{IH}$ was defined as rapid growth during the first 6 months of life. ${ }^{2}$ This growing may continue until 12 months.

This study was approved by the Noninterventional Clinical Research Ethics Board of Hacettepe University (GO 13/431). All the parents gave written informed consent for the study.

Physical examination findings were normal except for the cutaneous hemangiomas and routine laboratory tests were within normal limits for all cases. Twenty-two of 34 cases were followed regularly, 18 were administered oral propranolol treatment and 4 were followed with no treatment. All the hemangioma lesions were evaluated visually and the lesion sizes were measured by two researchers independently.

Peripheral venous blood samples of 34 cases were collected at the time of initial diagnosis. Additional blood samples were collected at the first and third months after diagnosis in 22/34 cases whom were followed-up regularly. Single peripheral venous blood samples were collected from the children in the ageand sex-matched control group. The serum samples obtained after centrifugation were stored at $-20^{\circ} \mathrm{C}$ until analysis. The remaining 12 patients were followed without treatment. Treatment indications for our cases were in accordance with the recommendations derived from the relevant medical literature such as life threatening complications, functional impairment or ulceration. ${ }^{7}$

Eighteen infants who received propranolol treatment had routine hematological examinations, hepatic and renal function tests and also, electrocardiogram and echocardiography to rule out any cardiac disease before treatment. They were hospitalized for two days and propranolol was administered initially at a dose of $0.5 \mathrm{mg} / \mathrm{kg}$ orally and the dose was increased to $2 \mathrm{mg} / \mathrm{kg}$ gradually in two days under monitoring.

All frozen serum samples were thawed to room temperature and analyzed for VEGF and bFGF serum levels using a quantitative enzymelinked immunosorbent assay (ELISA) method using human VEGF/bFGF 96 ELISA kits according to the manufacturer's instructions (Molecular Devices, England). Standard curves were created. The units of measurement for serum VEGF and bFGF were $\mathrm{pg} / \mathrm{ml}$.

The relationship between serum VEGF and bFGF levels and clinical course of the IH in the follow up were analyzed for 18 infants treated with propranolol. Clinical course and response to treatment of hemangiomas were assessed clinically and pictures were taken periodically. Two investigators independently evaluated the changes in the hemangiomas visually and also the sizes were measured in two maximal dimensions perpendicular to each other in $\mathrm{cm}$. Multiplication of 2 dimensions was calculated and their averages were recorded.

For each case, the follow-up percent changes were assessed both visually and by measurement by both researchers (designated as a) and the follow-up percent changes in the lesion sizes measured as described above (designated as b) were calculated. For evaluation of response of hemangiomas, patients were grouped according to the degree of treatment response in percentages [ $(a+b) / 2]$ as follows: group 1 for $<30 \%$ improvement or poor response, group 2 as $30 \%$ to $<70 \%$ improvement or good response and group 3 as $>70 \%$ improvement or excellent response. The response evaluation methodology was based on the system defined by Achauer et al. ${ }^{10}$ with modifications.

\section{Statistical analysis}

In the statistical analyses, the mean values in the subgroups were compared using t-test, 
and the median values between unrelated pairs of variables were compared using the Mann-Whitney U test or Kruskal-Wallis tests. Correlations between sets of data was analyzed with the Pearson test and linear regression analysis. The median percent of regression rates of the hemangiomas and median values of serum VEGF and bFGF at different time points were compared using the Friedman test. In every instance, a p-value $<0.05$ was considered statistically significant.

\section{Results}

Thirty-four patients with $\mathrm{IH}$ and 10 healthy controls were included in the study. Median age of 34 patients with IH (Female/Male, 29/5) was 5.5 months (0.8-37 months) and that of the control group (Female/Male, 5/5) was 4.9 months (2.1-23 months). Twenty patients were younger than 6 months (58\%) and 31 (91\%) patients were younger than 1 year. Twenty-four $(70 \%)$ patients had single cutaneous $\mathrm{IH}, 8$ had two lesions and the remaining two had 3 lesions (total 46 lesions in 34 patients). The localizations of lesions were as follows: $36(78 \%)$ in the head and neck, 7 (15\%) on the trunk and remaining 3 on the extremities. The greatest diameter of the hemangioma lesions ranged between 1 and

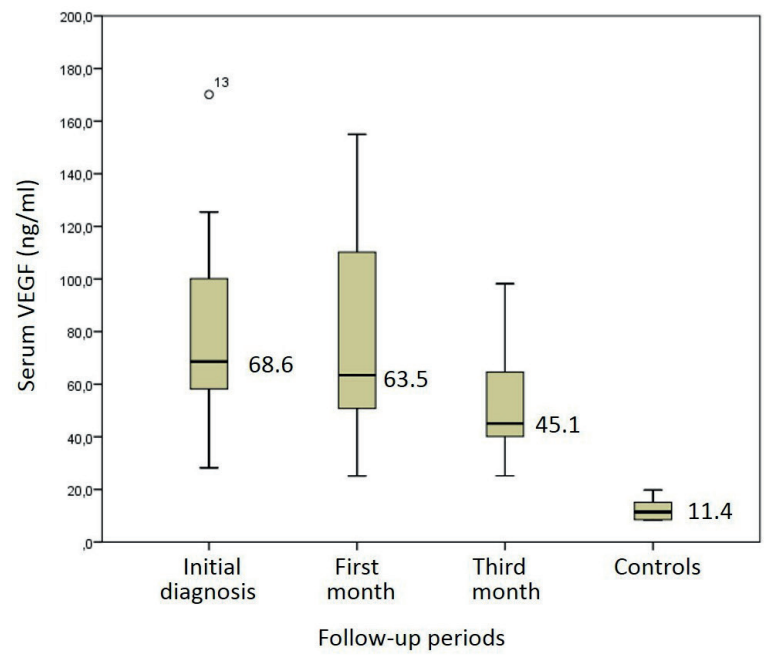

(a)
$8 \mathrm{~cm}$ (median $3 \mathrm{~cm}$ ) and the total lesion sizes (multiplication of 2 diameters) ranged between $1-25 \mathrm{~cm}^{2}$ (median $6 \mathrm{~cm}^{2}$ ); $62 \%$ of the lesions were $>4 \mathrm{~cm}^{2}$.

At the time of initial diagnosis; median serum VEGF levels were $58.5 \mathrm{ng} / \mathrm{ml}$ (25.3-190.2) in $34 \mathrm{IH}$ patients and $11.4 \mathrm{ng} / \mathrm{ml}(8.2-19.8)$ in the control group ( $\mathrm{p}<0.001)$; median serum bFGF levels were $11.1 \mathrm{ng} / \mathrm{ml}(4.8-16.6)$ in $34 \mathrm{IH}$ patients and $2.6 \mathrm{ng} / \mathrm{ml}(1.7-4.7)$ in the control group. Initial serum VEGF and bFGF levels were not correlated but both were significantly higher in IH cases than controls ( $\mathrm{p}<0.001)$. There were no significant differences in serum levels of VEGF and bFGF between patients younger than 6 months $(n=20)$ and older than 6 months $(n=14)$, and also between males and females. No correlation was found between total tumor size and serum levels of bFGF or VEGF. Median regression rates by appearance and size after 1 and 3 months were $-47.3 \%$ and $-58.3 \%(\mathrm{p}<0.001)$, respectively.

In 18 infants treated with propranolol, there were no major treatment-related adverse effects. Efficacy for propranolol treatment was evaluated as follows: excellent response in 5 patients $(27 \%)$, good response in 11 patients $(61 \%)$ and poor response in $2(11 \%)$ patients.

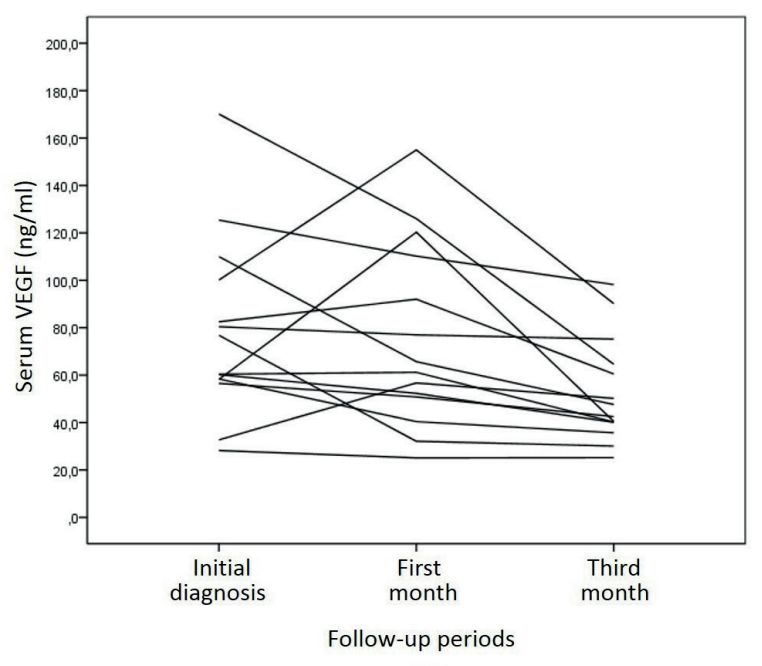

(b)

Fig. 1 a-b. Serial serum VEGF levels in 14 infantile hemangioma cases who were treated with propranolol and had serial measurements. 


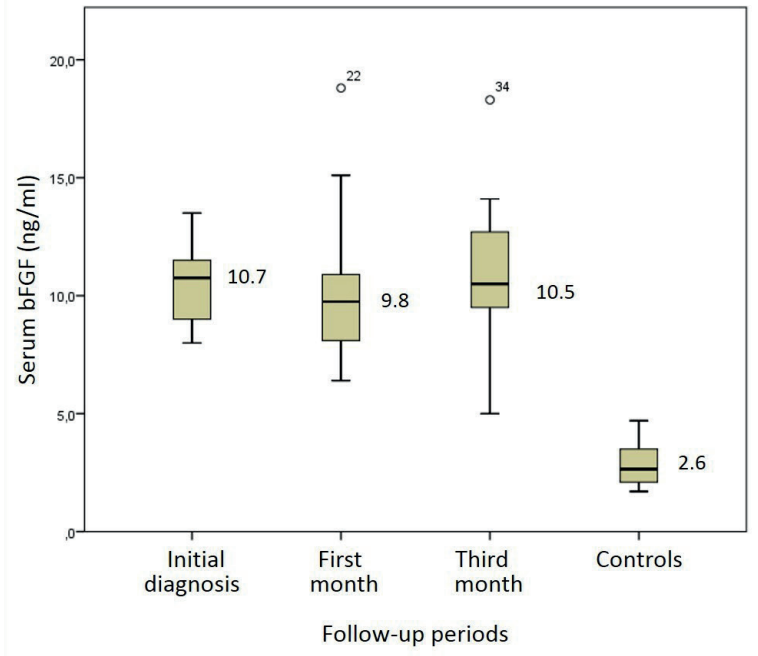

(a)

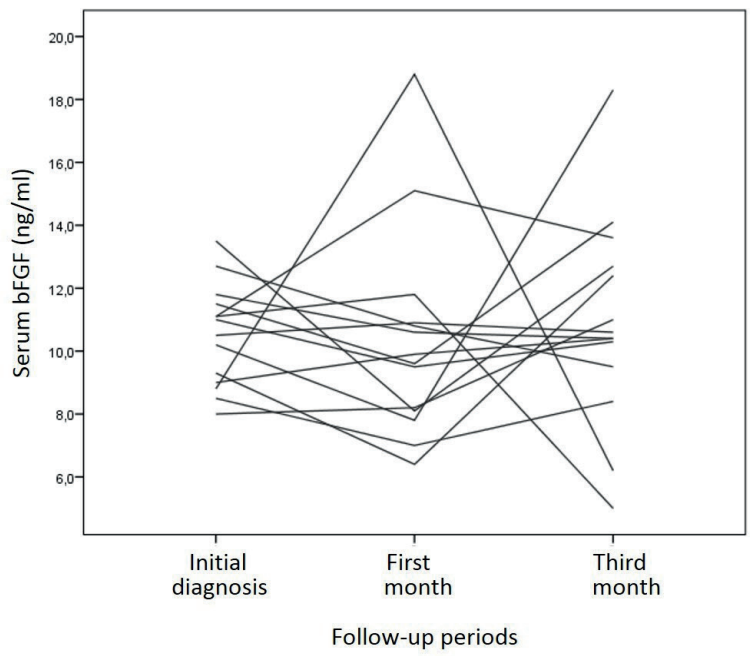

(b)

Fig. 2 a-b. Serial serum bFGF levels in 14 infantile hemangioma cases who were treated with propranolol and had serial measurements.

The total response rate was $89 \%$. No infants were withdrawn from treatment because of side effects. Follow up analysis was performed for 18 cases who received propranolol and had serial measurements at three-time points. In those 18 infants, at initial diagnosis, the first and third months median serum levels of bFGF were $11.1 \mathrm{ng} / \mathrm{ml}, 9.8 \mathrm{ng} / \mathrm{ml}$ and $10.5 \mathrm{ng} / \mathrm{ml}(\mathrm{p}=$ 0.8 ) and median serum levels of VEGF were $68.6 \mathrm{ng} / \mathrm{ml}, 63.5 \mathrm{ng} / \mathrm{ml}$ and $45.1 \mathrm{ng} / \mathrm{ml}(\mathrm{p}<0.001)$, respectively (Figs. 1 and 2). Both VEGF and bFGF were significantly higher than the control group at all the time points. The decrease in serum VEGF levels was most significant in the third month of follow-up.

\section{Discussion}

Both VEGF and bFGF are important proangiogenic growth factors that can stimulate both endothelial cell proliferation and differentiation and promote vasculogenesis. ${ }^{11}$ Excessive expression of VEGF and bFGF in hemangioma tissue has been confirmed in various studies, which parallels the proliferating phase of hemangioma growth., ${ }^{512-14}$ Although increased serum levels of VEGF in infants with $\mathrm{IH}$ compared to vascular malformations and healthy controls have been documented in many studies ${ }^{13,15-20}$, data examining the role of serum bFGF in IH were reported much less. 5,6,13,21-23 Przewratil et al. ${ }^{5,13}$ reported that serum bFGF levels were not elevated in patients with hemangiomas but were high locally around the lesion and they hypothesized that bFGF has a strong local activity and serum levels may not reflect its activity in tissues.

In our study, almost all of the hemangioma lesions were in the proliferation phase because $31(91 \%)$ patients were younger than 1 year. Our patients had significantly elevated serum VEGF and bFGF levels at the initial presentation compared with the control group which supports the hypothesis of increased activity of these cytokines. The results for elevated serum VEGF levels are parallel many similar studies. ${ }^{13,15-20}$ On the other hand, elevated serum bFGF levels contradict with that of Przewratil et al. ${ }^{5,13}$ but are comparable to findings reported in more recent studies. ${ }^{6,20,22}$ In agreement with our findings for $b F G F$, elevated levels of bFGF were also found in the urine of patients with $\mathrm{IH}^{16,23}$

Currently, oral propranolol is the preferred first-line treatment for $\mathrm{IH}$ and response rates to treatment with propranolol are high, ranging 
from $80 \%$ to $100 \%$. Based on case reports and series oral propranolol appears to have a favorable safety profile in children. ${ }^{24-26}$

Plasma VEGF levels significantly decreased in the following months after starting propranolol in our study. These results are consistent with the results in similar studies investigating the effects of propranolol on serum cytokines., ${ }^{6,17-19,22}$ The decrease in serum VEGF levels was much more significant after 12 weeks of propranolol treatment. Chen et al. ${ }^{18}$ reported that very high serum VEGF levels decreased significantly after one month compared to three months of treatment with propranolol. In a recent study, Przewratil et al. ${ }^{27}$ found no significant decrease in serum VEGF levels after propranolol treatment. They stated that their results were difficult to explain and did not support the theory of antiangiogenic properties of propranolol. Depending on our results, we propose that the measurement of serum VEGF may be a useful tool for predicting the course of $\mathrm{IH}$ and monitoring the efficacy of treatment with propranolol especially for deep-seated lesions.

The mechanisms of action of propranolol in IH remain unclear. Early effects of propranolol are proposed to be vasoconstriction, intermediate effects involve the inhibition of angiogenesis resulting from the blocking of proangiogenic cytokines such as VEGF and bFGF and longterm effects are characterized by induction of apoptosis in IH endothelial cells which result in tumor regression. ${ }^{28,29}$ Léauté-Labréze and colleagues $^{30}$ also postulated that propranolol may decrease expression of bFGF and VEGF.

Wu et al. ${ }^{6}$ reported that serum concentrations of VEGF, bFGF, and MMP-9 decreased significantly in the treatment group 8 weeks after medication. They concluded that the mechanism underlying the effects of propranolol may be associated with the downregulation of VEGF, bFGF and MMP-9 expression. Also, Babiak-Choroszczak et al. ${ }^{22}$ reported a decrease in serum VEGF and bFGF levels in the course of propranolol treatment of $\mathrm{IH}$.
In hemangioma derived stem cells, Zhang et al. ${ }^{12}$ showed that propranolol is capable of downregulating the expression of VEGF mRNA and decreasing VEGF protein levels. They also found that propranolol can downregulate the expression of bFGF, although not as pronounced as that observed for VEGF expression. ${ }^{12}$

Our results did not confirm the effect of propranolol treatment on bFGF levels, since the expression of bFGF remained elevated during propranolol therapy in contrast to VEGF levels. This finding might indicate different effects of bFGF in the pathogenesis and course of IH.

Initial serum VEGF and bFGF levels were not correlated in our study. Our results are consistent with a recent study by El Raggal et al. ${ }^{20}$ In our study, no correlation was found between the serum cytokine levels and patient ages. Our results are consistent with other reports confirming a lack of gender and age differences in serum VEGF and bFGF levels in $\mathrm{IH} \cdot{ }^{17,19}$ No such correlation was found in the control group as well.Another finding of this study was the lack of correlation between the serum VEGF and bFGF levels and the size of the lesions.

Propranolol has revolutionized the treatment of IHs while the exact mechanism of action is poorly understood. ${ }^{7,8,26}$ Propranolol may be exerting its effect primarily through the inhibition of VEGF. Other mechanisms might also be dominant in inhibition of IH growth by propranolol beyond effects on bFGF. We may speculate that initially high serum bFGF levels may reflect the bFGF activity in IH pathogenesis, but may not be useful for monitoring the treatment response and effectiveness of propranolol during followup.

This study has some limitations. We studied only a small cohort of patients. Additionally, the study included limited measurement values as an objective outcome assessment. These findings require further study and a large cohort of patients and the control group. 
In conclusion, serum VEGF and bFGF levels were significantly elevated in IH. Serum bFGF levels didn't change over time. The results of our study add significant information regarding serum levels of both VEGF and bFGF during propranolol treatment which may help predict the mechanism of action of propranolol. Measurement of VEGF may be a useful tool for predicting the course of $\mathrm{IH}$ and monitoring the efficacy of propranolol.

\section{Acknowledgement}

This study was supported by a grant from the Scientific Research Projects Coordination Unit of Hacettepe University.

\section{REFERENCES}

1. Ma X, Zhao T, Xiao Y, et al. Preliminary experience on treatment of infantile hemangioma with lowdose propranolol in China. Eur J Pediatr 2013; 172: 653-659.

2. Smolinski KN, Yan AC. Hemangiomas of infancy: clinical and biological characteristics. Clin Pediatr (Phila) 2005; 44: 747-766.

3. Hagen R, Ghareeb E, Jalali O, Zinn Z. Infantile hemangiomas: what have we learned from propranolol? Curr Opin Pediatr 2018; 30: 499-504.

4. Folkman J. Clinical application of research on angiogenesis. N Engl J Med 1995; 333: 17571763

5. Przewratil P, Sitkiewicz A, Andrzejewska E. Serum levels of basic fibroblastic growth factor (bFGF) in children with vascular anomalies: another insight into endothelial growth. Clin Biochem 2010; 43: 863867.

6. Wu S, Wang B, Chen L, et al. Clinical efficacy of propranolol in the treatment of hemangioma and changes in serum VEGF, bFGF and MMP-9. Exp Ther Med 2015; 10: 1079-1083.

7. Krowchuk DP, Frieden IJ, Mancini AJ, et al; Subcommittee on the management of infantile hemangiomas Clinical practice guideline for the management of infantile hemangiomas. Pediatrics 2019; 143: e20183475.

8. Satterfield KR, Chambers CB. Current treatment and management of infantile hemangiomas. Surv Ophthalmol 2019; 64: 608-618.
9. Yang H, Hu DL, Shu Q, Guo XD. Efficacy and adverse effects of oral propranolol in infantile hemangioma: a meta-analysis of comparative studies. World J Pediatr 2019; 15: 546-558.

10. Achauer BM, Chang CJ, Vander Kam VM. Management of hemangioma of infancy: review of 245 patients. Plast Reconstr Surg 1997; 99: 1301-1308.

11. Gupta K, Zhang J. Angiogenesis: a curse or cure? Postgrad Med J 2005; 81: 236-242.

12. Zhang L, Mai HM, Zheng J, et al. Propranolol inhibits angiogenesis via down-regulating the expression of vascular endothelial growth factor in hemangioma derived stem cell. Int J Clin Exp Pathol 2014; 7: 48-55.

13. Przewratil P, Sitkiewicz A, Wyka K, Andrzejewska E. Serum levels of vascular endothelial growth factor and basic fibroblastic growth factor in children with hemangiomas and vascular malformationspreliminary report. Pediatr Dermatol 2009; 26: 399404.

14. Frischer JS, Huang J, Serur A, Kadenhe A, Yamashiro DJ, Kandel JJ. Biomolecular markers and involution of hemangiomas. J Pediatr Surg 2004; 39: 400-404.

15. Zhang L, Lin X, Wang W, et al. Circulating level of vascular endothelial growth factor in differentiating hemangioma from vascular malformation patients. Plast Reconstr Surg 2005; 116: 200-204.

16. Zhang L, Chen Q, Li D, Li XW, Wang HG, Li GZ. Evaluation of the role of serum vascular endothelial growth factor and urinary basic fibroblast growth factor in differential diagnosis of vascular anomalies. Zhonghua Yi Xue Za Zhi 2011; 91: 1092-1095.

17. Yuan WL, Jin ZL, Wei JJ, Liu ZY, Xue L, Wang XK. Propranolol given orally for proliferating infantile haemangiomas: analysis of efficacy and serological changes in vascular endothelial growth factor and endothelial nitric oxide synthase in 35 patients. Br J Oral Maxillofac Surg 2013; 51: 656-661.

18. Chen XD, Ma G, Huang JL, et al. Serum-level changes of vascular endothelial growth factor in children with infantile hemangioma after oral propranolol therapy. Pediatr Dermatol 2013; 30: 549-553.

19. Ozeki M, Nozawa A, Hori T, et al. Propranolol for infantile hemangioma: effect on plasma vascular endothelial growth factor. Pediatr Int 2016; 58: 11301135.

20. El-Raggal NM, El-Farrash RA, Saad AA, Attia EAS, Saafan HA, Shaaban IS. Circulating levels of vascular endothelial growth factor and basic fibroblastic growth factor in infantile hemangioma versus vascular malformations. Clin Appl Thromb Hemost 2018; 24: 663-668. 
21. Yang XJ, Jiang $\mathrm{YH}$, Zheng JW, Hong L, Zhou Q, Qin ZP. The role of serum basic fibroblast growth factor, estradiol and urine basic fibroblast growth factor in differentiating infantile haemangiomas from vascular malformations. Phlebology 2011; 26: 191-196.

22. Babiak-Choroszczak L, Giżewska-Kacprzak K, Gawrych E, et al. Serum concentrations of VEGF and bFGF in the course of propranolol therapy of infantile hemangioma in children :are we closer to understand the mechanism of action of propranolol on hemangiomas? Adv Clin Exp Med 2018; 27: 703710 .

23. Zhang L, Lin XX, Qi ZL, et al. Role of urinary basic fibroblast growth factor in differentiating hemangiomas from vascular malformation. Zhonghua Wai Ke Za Zhi 2006; 44: 186-188.

24. Léaute-Labrèze $C$, Boccara $O$, Degrugillier-Chopinet C, et al. Safety of oral propranolol for the treatment of infantile hemangioma: a systematic review. Pediatrics 2016; 138: e20160353.

25. Léauté-Labrèze $C$, Hoeger $P$, Mazereeuw-Hautier $\mathrm{J}$, et al. A randomized, controlled trial of oral propranolol in infantile hemangioma. N Engl J Med 2015; 372: 735-746.
26. Chen ZY, Wang QN, Zhu YH, et al. Progress in the treatment of infantile hemangioma. Ann Transl Med $2019 ; 7: 692$.

27. Przewratil P, Kobos J, Wnęk A, et al. Serum and tissue profile of VEGF and its receptors VGFR1/R2 in children with infantile hemangiomas on systemic propranolol treatment. Immunol Lett 2016; 175: 4449.

28. Rotter A, de Oliveira ZNP. Infantile hemangioma: pathogenesis and mechanisms of action of propranolol. J Dtsch Dermatol Ges 2017; 15: 11851190.

29. Storch $\mathrm{CH}$, Hoeger PH. Propranolol for infantile haemangiomas: insights into the molecular mechanisms of action. Br J Dermatol 2010; 163: 269274.

30. Léauté-Labrèze $C$, Dumas de la Roque E, Hubiche T, Boralevi F, Thambo JB, Taieb A. Propranolol for severe hemangiomas of infancy. N Engl J Med 2008; 358: 2649-2651. 